\title{
CHANGING STATUS OF TRIBAL WOMEN, IN VISHAKAPATNAM
}

\section{DISTRICT OF ANDHRAPRADESH}

\author{
S. NARASIMHAM ${ }^{1} \&$ D. V. SUBBARAO ${ }^{2}$ \\ ${ }^{1}$ Research Scholar, ANGRAU, Guntur, Andhra Pradesh, India \\ ${ }^{2}$ NABARD Chair Professor, ANGRAU, Guntur, Andhra Pradesh, India
}

\begin{abstract}
Schedule Tribes (ST's) are Indian population groups that are explicitly recognized by the constitution of India order 1950. The order lists 744 tribes across 22 states in its first schedule. In Andhra Pradesh 34 types of Schedule Tribes are living in 13 districts. ST's are 5.7\% are in total population of Andhra Pradesh. They have rich heritage along with their innocent life style. The tribal women, constitute like any other social group, about half of the total population. Tribal societies generally view gender as complimentary and egalitarian, where each role is defined but complimentary to the other. Men focus on cultivation and women plant and gather the food, thus both roles are necessary and complimentary in the holistic relationship of the family/community. Traditionally, tribal women and men had equal access to lands, animals and resources, and this was beneficial to the collective. However, as a result of the integration and assimilation efforts of dominant culture, capitalistic systems and the ideal of individual ownership, tribal women in particular experience fewer opportunities to access their natural resource and lands. As a consequence Gender relations within tribal society have been changing. The present paper is based on empirical study carried out in the Visakhapatnam district of Andhra Pradesh that highlights the plight of tribal women in present scenario.
\end{abstract}

KEYWORDS: Schedule Tribes, Individual Ownership.\& Natural Resource

Received: Sep 16, 2017; Accepted: Oct 07, 2017; Published: Oct 28, 2017; Paper Id.: IJESRDEC20172

\section{INTRODUCTION}

The gender relations in a tribal society seem to be relatively egalitarian with women enjoying quite a high social status and economic value compared to their non-tribal counterparts. Role of women is not only of importance in economic activities, but her role in non-economic activities is equally important. The tribal women work very hard, in some cases even more than the men. The tribal women have a freedom, and a self-expression. With the onset of development programmes economic changes are taking place, which affect men and women differently. This inequality arising from the development process calls, for a detailed scrutiny because, it has resulted in not only inequality between tribals and nontribals, but also among tribals on gender basis. Majority of the tribal societies are patriarchal. Women are not equal to men as such, but had higher status vis-a-vis non-tribal women, both their relatively high status and children's upbringing, depended on abundant resources and partial control that, they exercised over them. In other words, tribal women owed their relatively high status both to the abundance of resources and a clear division in their societies between the family and the social sphere. The man represented the family in the society and woman as the main decision maker in the family economy, production, and social relations. Tribal women enjoy a greater social status with regard to control over resources. This ensures their active participation and decision-making with regard to land utilization, agriculture and powers over cash flow 
in a tribal economy. The fact that the woman controlled the family economy was the main reason why her status depended on abundant resources. As such, she had a bigger vested interest in treating them renewable, that is, in their sustainable use. The vested interests, her control over the family economy and her consequent relatively high status depended on the resources remaining as common property resources (Pathy, 1988). Much of this has changed, during the decades of planned development. Modernization tends to be more and more individual land ownership oriented, and as a result destructive of the woman's status (Fernandez and Barbora, 2002). These tribal women who sustained themselves on the natural resources, had to face economic impoverishment, followed by loss of social status.

\section{Changing Scenario}

There are a large number of processes, through which tribals have lost access to land and forests essential, for their survival and livelihoods. These don't only include alienation of land, which is legally owned by the tribals through debt mortgaging and sale, but also loss of access to land through reservation of forests, loss of traditional shifting cultivation land through Survey and Settlement, displacement, unsuitable and unimplemented land reform laws etc. Over a period of time, all these processes have led to loss of control and access to livelihood support systems vital to their existence, marginalizing and destitution of tribal communities. Influx of non-tribals, since the last two centuries, many of whom are more capable of negotiating state enforced legal and tenure systems, have pushed tribal communities to the bottom of the local power hierarchies, even in areas where they are in majorities. In areas where tribals are in minorities, their conditions, along with that of dalits, are even more miserable and powerless. Lack of ownership and claim over land and other factors of production is one of the fundamental reasons behind the current situation. Another important cause of displacement in schedule $\mathrm{V}$ areas is large-scale mining and industrial projects. Given the liberalization of mining and industrial policies which allows for direct foreign investments, large number of mining and industrial projects is in the pipeline, mostly to be located in scheduled areas. The situation in these scheduled areas are already extremely disturbing, with large scale mining leading to displacement of tribal, destruction of their livelihood support system including forests and water sources, large scale air and water pollution, and influx of outsiders. For over a decade-and-a-half the government has been pushing the agenda of the corporate sector, resulting in unprecedented trauma to the tribal people depending on land and natural resources for survival. Projects varying from multi-purpose dams, reservoirs, power plants or any other industries have led to large-scale displacement, destruction of livelihood, cultures and also the physical environment. While local communities were adversely affected, the issue of women in such situations has never been considered. In the forest areas the pattern of industrialization is restructuring social relations. Labour roles are changing with the transition from traditional land- and forest- based livelihood. With this shift in labour roles and traditional livelihoods, gender roles are shifting as well. Where men and women had previously worked together in agricultural activities, now men are working daily in the mines to earn cash income, whereas they would have previously worked to support their families through agricultural production. Women are staying at home, to carry out only household duties with the degradation and alienation of lands. With the individual Patta becoming the norm of land ownership, power has been transferred to man and from him to his son. The increasing vulnerability of land- and forest- dependent people in rural India has conflated pressure, to retain what remaining land and resources they do hold. Now tribal women are prohibited from owning land without the support of their father, husband, son or brother, so that if a woman is married to a non-indigenous person, the land can stay with the male relative and with the tribal community. Livelihoods of forest dependent peoples, especially women, are adversely affected by forced evictions. Non-timber forest produce forms a major source of income, for many tribal communities. Women are almost exclusively involved in collection, storage, processing and marketing of minor 
forest products such as fodder, thatching, and medicinal herbs. However increased government control of forests and minor forest products are adversely affecting livelihoods choices of Tribal and forest dependent women. The woman seizes to be the main decision maker, in the family economy and becomes dependent on man (Thekkekara, 1993). Krishna (2005) says that, the swift transformation of production systems, land use and livelihoods in recent decades has affected gender relations, leading in many cases to marginalization of women. Further, with the establishment of industries and various development projects, by the Government, each member of the family were to be given a job, whereby women were never considered. Jobs were normally given to men, considered heads of family, which were often temporary or daily wagers. Thus, in comparison to women, the men folk among tribals forged ahead, in acquiring the modern privileges.

\section{REVIEW OF LITERATURE}

Gurnug (1998) suggests that, the social and economic status of tribal women is low because of social hierarchy and economic deprivation. The difference in land holding, food security, allocation of resources and role in decision making affects and determines their socio economic status. Bhasin (2007) has carried out her study about tribal women in different geographic region i.e. Ladhak, North Eastern Region, Rajasthan and her findings show that, the tribal women possess a lot of importance in tribal communities. Awias et al. (2009) stated that, tribal women have major role in comanagement of their natural, social and economic resources. But, still they suffer a lot; they are backward due to a traditional outlook, illiteracy, superstition, and submissive role in decision making, social evils and many other cultural factors. Geetha Menon (1992) reveals that, the impact and the loss of common property resources are very severe, on tribal women. She shows that, the hardships of the tribal women have been increasing. Thus tribal women are the major victims of the deprival of the traditional rights of the tribals, in common property resources. Recent research indicates that, violence against tribal women is increasing while kinship bonds are decreasing (Panda \& Snehalata, 2008). The practice of eliminating widows through "witch hunting" has been condemned, throughout the country. Nutritional intake is decreasing due to decreased traditional cultivation and agricultural activities, and as a result peoples' immunity and health is declining as seen in the increasing incidences of diseases, like tuberculosis and malaria (Basu and Kshatriya, 1989; Basu et al., 1993; Chopra and Makol, 2004). Awais et al. (2009) point out that, tribal women face problems and challenges in getting a sustainable livelihood, and a decent life due to the environmental degradation and the interference of the outsiders. According to Fernandes et al. (2001), in Andhra Pradesh, Orissa and West Bengal, tribal women deprived of natural resources that are their sustenance, complained of not having any work. These were the sources of their high status and of their economic utility. With their disappearance, they felt that their community did not have any use for them. They are reduced to being housewives alone, with no opportunity to work outside the house and make a contribution to the family economy. The review of literature clearly indicates that, various researchers have highlighted the changing status of women in the tribal society.

\section{Profile of Visakhapatnam District in Andhra Pradesh}

Visakhapatnam is the highest Scheduled Tribe Population district, in the State of Andhra Pradesh and is situated in its north eastern part. Most of the tribal population (14.5 percent of total population), stay in forest areas and are engaged in agriculture. Their livelihood depends on forest $\&$ other natural resources. Their age old traditional practices are conservation oriented and form a true example of sustainable lifestyle. Visakhapatnam is one of the last natural resource frontiers in India - perhaps in the world. The district has rich forests and natural resources, and is known for its waterfalls and scenic beauty. Andhra Pradesh is among the richest Indian states, in terms of mineral wealth, with 44 varieties of major 
minerals, including diamonds. The main tribes of area are Konda Dora, Bagata, Valmiki, Kondh, Yerukula and Porja. In addition to the above tribes, Gadada, Mukha Dora, Kotia, and Generic Tribes, also present in Vishakapatnam District.

\section{MATERIALS AND METHODS}

Present study is an in depth exploratory analysis of the lives of tribal women in Visakhapatnam district of Andhra Pradesh. Purposive sample of 300 tribal women in the age group of 15-55 years, residing in Visakhapatnam were included. Visakhapatnam being the headquarters of the district, it was decided to collect the sample from the villages, within the radius of 35 to $40 \mathrm{Km}$ of the town. 85 tribal women from Konda Dhora tribe, 26 from Bagatha,16 from Kondh, 18 from Valmiki, 83 from Kotia, 30 from Pojra and 42 from Gadaba were included in the sample. Informal interviewing with the help of interpreter was used, to collect information.

\section{RESULTS AND DISCUSSIONS}

The distribution of the respondents, according to different age categories clearly indicates that, a majority of the respondents belonged to an economically active age group. The majority of tribal women under study were married.

Table 1: Socio Demographic Characteristics of Tribal Women

\begin{tabular}{|c|c|c|c|}
\hline Characteristics & Category & Number & Percentage \\
\hline \multirow{5}{*}{ AGE } & $15-25$ years & 85 & 28.9 \\
\hline & 25-35 years & 88 & 29.4 \\
\hline & $35-45$ years & 77 & 25.8 \\
\hline & $45-55$ years & 106 & 55 \\
\hline & 55 and above & 22 & 12 \\
\hline \multirow{4}{*}{ MARITIAL STATUS } & Never married & 40 & 11 \\
\hline & Married & 218 & 73.2 \\
\hline & Once married presently single & 44 & 15.1 \\
\hline & No children & 42 & 14.2 \\
\hline \multirow{3}{*}{ NUMBER OF CHILDERN } & 2 & 84 & 24.1 \\
\hline & $2-3$ & 162 & 53.9 \\
\hline & 3 and above & 10 & 11.1 \\
\hline \multirow{5}{*}{ EDUCATION } & Illiterate & 204 & 68.2 \\
\hline & Primary & 52 & 17.2 \\
\hline & Middle & 16 & 16.8 \\
\hline & Metric and above & 30 & 9.9 \\
\hline & House wife & 54 & 17.1 \\
\hline \multirow{2}{*}{ OCCUPATION } & Labour & 193 & 64.6 \\
\hline & Agriculture & 51 & 16.9 \\
\hline \multirow{3}{*}{ INCOME } & Upto Rs. 5000/per month & 204 & 68.4 \\
\hline & Rs.5000 to $10000 /$ per month & 69 & 21.9 \\
\hline & Rs $>10000 /-$ per month & 25 & 7.9 \\
\hline
\end{tabular}

The incidence of widowhood and divorce, though rare is not uncommon. Taking into account the educational attainment of the respondents under study, it is difficult to find any marked difference in the tribes, since 68 percent of the respondents were illiterate. Results show that more than 60 percent of the respondents worked as laborers. It is necessary to mention here that most of the respondents did not own land and they turned up as daily wagers. The impact of ongoing aggressive growth on women could be broadly divided under two heads:

- $\quad$ Socio Cultural

- Economic 


\section{Socio-Cultural Impact}

Tribal society of Andhra Pradesh is alive on a culturally networked web. Landed property in tribal communities is understood as a sacred inheritance from the ancestors and the sons who inherit them are the custodians of this land. They do work on the land and draw their sustenance, but they also have a responsibility to safely hand over this property to the next generation. When the onslaught of development projects uproots them from their ancestral place, they are socially ruined. They are deprived of the same social and cultural meaning when they start living in another place. As a result, the well-knit social fabric of tribal community gets completely shattered. Their society breaks. They find it difficult and often impossible to begin a new society where they can live with their old values, old relations and old meaning of life and women are the worst hit group due to breakdown of society. The social and cultural web or network gets dismantled after displacement and so does the support system the community. The loss of land negatively contributes in the disruption of family bonds. The support and help the families provide to each other is not available after displacement. Women suffer the most due to breakdown of the social network.

\section{Increase in Alcoholism among Men}

Men start drinking or increase drinking as a 'coping' mechanism. As the man, who has lost his traditional occupation- farming, goes around looking for jobs, frustration builds up in him, which he takes out on the women of the house. Results show that 42.7 percent of the respondents had marital conflict due to alcoholism. The influx of hordes of outsiders in the area affects their cultural and social values. The material culture that the outsiders bring in along with them affects the locals. They start feeling inferior about their own culture. The culture of the group perceived as superior who are now their neighbors, is superimposed on them and here begins a cultural crisis. In other words the local society, which earlier had a distinctive culture, faces a peculiar problem hitherto unheard of - that of cultural identity.

\section{Social Dignity of Women Going Down}

The disintegration of the community network caused by investment invaders affect the women, more severely than men. Wife's disrespectful behaviour pattern towards her husband, her disobedience and being nagging type were the main precipitating factor, for spousal quarrel among Gadaba tribes. Those who had no land earlier and were dependent mainly on sharecropping or rendering services to the community and/or solely dependent on common property resources, also lose their market and their access to the common property. Women face a new situation where jobs, if there are any, generally go to the men of the family, the compensation amount goes to men, and they are left with no work. Among Pojra tribe women are not allowed to plough the fields. Gadaba and Porja tribe women are prohibited from trading. Only Bagata women work in the houses of non-tribals, as domestic help.

\section{Migration of Tribal Girls Due to Loss of Livelihood}

Migration of tribal girls to other states, in search of livelihood is probably the severest fallout of aggressive growth and displacement, in modern era. Loss of land and resultant loss of work has pushed tribal girls to migrate. Mechanization of construction works - roads, buildings and others, has robbed them off their livelihood which they earned selling their physical labour. Though a small portion of the labour could still be used in these works, along with machines, a big chunk was thrown out of work. 


\section{Women Forced to Sell Toddy and Geeluga Kallu for Livelihood}

All across tribal areas and especially in hamlets that surround developed cities, women can be spotted selling toddy on road sides, babies slung on their backs. Traditionally, tribal women have extracted toddy not for commercial use but for use during festivals. Now selling it seems to have become a new livelihood option, for those women whose families have borne the brunt of aggressive development and loss of livelihood.

\section{Women are Turning to Construction Labour}

Construction work in industrial areas is cashing on availability of cheap labour, created by the loss of livelihood as a result of aggressive growth, through industrialization. Women may find employment at construction sites, but they lose self-esteem in the process and become vulnerable to sexual exploitation, by contractors. Instances of sexual exploitation occur more with women. Results show that more than 60 percent of the respondents worked as laborers. It is necessary to mention here that most of the respondents did not own land and they turned up as daily wagers. It has been found that in majority of tribes under study, heads of the household were engaged in menial types of occupations which included labourers in farms or construction workers. Majority of the tribals were poor, as their total monthly income was less than Rs. 5000. Majority of the respondents admitted that, they are paid less than men. Majority of the respondents belonging to Kotia tribe (92.9 percent) followed, by Yerakula tribe (87.5 percent) and then Mukha Dora tribe (83.3 percent), who reported differentials in wages of men and women. They conferred that, it was due to the economic pressure that, they were accepting the low wages.

\section{CONCLUSIONS}

The analysis given in this paper shows that, though development projects are important for the progress of the livelihood of the people affected by them. It is true more in case of tribal women. One can deduce from the above discussion that, tribal women have been severely affected by the development. With the alienation of the natural resources, the tribal woman seizes to be an economic asset to the family. The impact of this is felt, not only in the economic field but also in the social arena. She seizes to be autonomous. Tribal women are particularly vulnerable, to violence both within their own communities and in the broader society. Tribal women experience many kinds of violence, in times of peace and war, including beating and forced labour. They are trafficked for prostitution and forced labour. Globalization and economic liberalization have often destroyed indigenous subsistence economies and displaced tribals from their land. Tribal women have lost their livelihoods. Poverty has contributed to displacement of indigenous communities. There has also been an increase in migration of tribal women, in search of employment, to cities, where they face the danger of exploitation and inhumane treatment. Forced migration has led to destruction of indigenous lifestyles and compounded the problems faced by tribal women.

\section{REFERENCES}

1. AwaisMohamad, TosibAlam and MohdAsif, 2009. "Socioeconomic Empowerment of Tribal Women: An Indian Perspective”, International Journal of Rural Studies, Vol.16, No.1, October.

2. Basu, S. and Kshatriya, G., 1989. Fertility and mortality in tribal populations of Bsatar district, Madbya Pradesh, India. Biology and Society, 6: 100-112.

3. Basu, S. K., Jindal, A. Kshatriya, G. K., Singh, P., Roy, P. and Sharma, K. K. N. 1989. Epidemiological Investigation of Haemoglobinopathies and allied disorders, nutrition and physical growth trends, health profile, health seeking behaviour and 
their environmental correlates for promotion of health care among Scheduled Tribes and Scheduled Castes of Visakhapatnam district. Madhya Pradesh: Project Report. Department of Population Genetics\& Hum. Dev. NIHFW, New Delhi. (DGHS).

4. BhasinVeena, 2007. 'Status of Tribal Women in India'. Study of Home Communication Sciences., 1(1): 1-16.

5. Chopra, K. and Makol, N., 2004. "Common health problems encountered by tribal community in Visakhapatnam district" Health \& Population-Perspectives \& Issues 27(1),40-48.

6. Fernandez, Walter, NafisaGoga D’Souza, Arundhuti Roy Choudhury and Mohammed Asif, 2001. Development- Induced Displacement, Deprival and Rehabilitation in Andhra Pradesh 1951-1995: Its Extent, Nature and Impact. New Delhi: Indian Social Institute

7. Fernandez, W. and Barbora, S., 2002. Modernization and changing women's status in the North Eastern India, Guwahati, North Eastern Social Research Centre

8. Gurung, B. 1998. Towards an understanding of mountains, development and knowledge processes: a study of the Mewahang Rai of Eastern Nepal. University of Hawaii, USA. (unpublished Ph. D. thesis)

9. Krishna, S. 2005. “Gendered Price of Rice in North-Eastern India”, Economic and Political Weekly, Vol 40, Issue 25, June $18,2005$.

10. Menon Geetha, 1992. "Tribal Women: Victims of the Development Process," in Walter Fernandes (ed). National Development and Tribal Deprivation. New Delhi: Indian Social Institute, pp. 208225.

11. Panda, Z. and Snehalata, 2008. "Socio-Economic Status and Domestic Violence against Tribal Women", Man \& Development, Vol. XXX, September; No. 3, pp. 55-68.

12. Pathy, J., 1988. Ethnic minorities in the process of Development, Jaipur, Rawat Publications.

13. Thekkekara, S., 1993. "Historic Adivasi Sangam at Mananthavady" Social Action, 43(1), Jan-Mar, pp 88-92. 
